Encounters on Education

Volume 5, Fall 2004 pp. 1 - 8

\title{
Introduction
}

\section{Perspectives on Human Rights and Education}

\section{Fernando Gil}

Universidad Complutense, Spain

\section{Michael E. Manley-Casimir}

Brock University, Canada

\begin{abstract}
$\mathrm{T}^{\mathrm{s}}$ HIS SPECIAL ISSUE OF Encounters on Education / Encuentros sobre Educación/ Rencontres sur l'Éducation provides a forum for examining issues of human rights and education set within an intercultural perspective involving Canada, Latin-America and Spain. Such an undertaking raises a whole host of questions and difficulties in interrogating the varying experiences of the countries represented here. Quite apart from the obvious geographical, historical, social and cultural differences between and among these countries, the central problem in such an undertaking is to acknowledge, if not fully to take account of, the markedly different political cultures and political histories of the countries in this set. The historical and political experiences of the countries that collectively form LatinAmerica, for example, differ markedly from each other, though there may in some cases be points of similarity. In the same way the political and historical experiences of Spain and Canada are unique. Not surprisingly, therefore, the papers in this special issue only begin to scratch the surface of the distinctiveness of the political cultures upon which the universal notions of human rights are being grafted. Not only are there differences in political culture, there are also attendant differences in the development of a rights' consciousness among the countries represented here. Nevertheless, the papers do begin to address the issues of human rights and education and have the potential to engender a dialogue that cuts across the differences between our respective countries.
\end{abstract}




\section{Perspective on Latin-America}

The situation in Latin-America is captured by the contribution made to this special issue by Diego Iturralde and Ana Maria Rodino. Writing from their perspective in the Inter-American Institute of Human Rights, their analysis offers a rich panoramic view of the state of affairs in Latin-America. Since each Latin-American country has its own particular history and political circumstances respecting human rights and education, it is potentially very difficult to establish common bases for all Latin-American contexts. Professors Iturralde and Rodino overcome this difficulty. Just because some countries have experienced excruciatingly difficult political circumstances where human rights have been trampled under the jackboot of tyranny and 'dictaduras,' their preoccupation with issues of human rights is stronger than in other parts of the world. The hypocrisy of the attitudes and postures in such regimes towards human rights has nowadays become quite clear. The renewed commitment in these countries towards human rights is evidenced in numerous pedagogical initiatives, in claims of an education linked to democratic values, and in detailed revisions of legislation, curricula, textbooks and teacher training programmes. As in other places and other contexts, the gross abuses of fundamental human rights under these regimes has decisively contributed to a much greater political awareness and commitment to the promotion, through education, of a solid human rights culture.

\section{Perspective on Spain}

In Spain, human rights only started to be taken seriously with the arrival of democracy, and in particular following the ratification of the Constitution in 1978. The Constitution opened up two fronts: firstly, it acknowledged that constitutional rights are ultimately founded on human rights; they are the political and moral foundation of the Constitution. All Spanish citizens may have recourse should the need arise, to higher judicial bodies such as the Strasbourg Court, if they feel that their human rights have been violated. Secondly, the 1978 Constitution explicitly recognised the right to education, linking this to international documents like the Universal Declaration of Human Rights. The recognition of the right to education establishes both social and educational legitimacy by affirming foundational values in a constitutional framework upon which future generations may rely to create projects for human development.

The United Nations Declaration of Human Rights not only recognized education as a fundamental human right, it is the only right explicitly charged with the responsibility of promoting and disseminating the other rights. This starting point is very significant because, as Katarina Tomasevski, Special Rapporteur on the right to education of the UN Commission on Human Rights, noted in her book "Education Denied: Costs and Remedies", some educational systems are worse than no schooling at all. Indeed, education is not a human right just in order to extend literacy. Education must, in its content and form, be provided in such a way that it constitutes a genuine human right. There may be educational systems, schools, and teachers that in their practice infringe the right to education as a human right. We return to this idea later. 
Currently, this proposition constitutes one of the most fascinating and difficult intellectual challenges for those of us who spend time reflecting on pedagogical questions: When does education express in practice the foundations that constitute human rights? How can we differentiate between educational systems on the basis of human rights? Under what conditions may we assert that one school shows greater respect and regard for human rights than another? Likewise for a teacher? And for parents?

From 1978 to the present day, pedagogical research in the academy about education and human rights has developed along two different but complementary lines. The first, of a more political and ideological nature, refers to the meaning of the right to education as a human right. The second, of a more pedagogical nature, refers to the teaching of human rights.

In the first case, the political approach, research has followed a clear path from more general to more specific questions. Initially, the aim was to achieve a universal right to education. Although this objective was already provided for in the General Education Act of 1970, it could only actually be achieved by means of political will rooted in democratic values based on equal opportunities. Access to education for all gave rise to other questions related to this right: co-education, school choice, the right of private schools to define their own axiological character, the creation of school boards, the expansion of economic aid, the drafting of legislative texts to replace pre-democratic legislation, changes in the curriculum and school textbooks, etc. In retrospect the promotion of the right to education as a fundamental human right was not the underlying motive behind these developments rather the political rhetoric at the time was more about the democratisation of education. Similarly, the rhetoric of human rights was used both to support and to criticise specific educational policies. Throughout these years, the influence of various educational laws, both those drafted by the right and by the left, have been decisive in explaining and justifying the swings between proposals that see the right to education as a right linked to liberal policies, or to social protection policies. Unfortunately, in Spain we do not have a stable political consensus on education. Perhaps this is because our democracy is still in its infancy, i.e. because certain ideological disputes have yet to find essential points of convergence. The absence of consensus on the direction and character of educational policy encourages political disagreement, which confuses and irritates parents and teachers through the constant, and sometimes inexplicable, "back and forth".

Currently, the debates concerning how the right to education should be expressed focus on the following issues: the presence of religious education in schools; the public financing of private schools that apply for funds; the integration of immigrant children; the way of dealing with students who fail subjects, the accountability of the school system, and tests for certain educational levels and for university entrance. These questions are very seldom argued from the point of view of education as a human right, which suggests that this right is seen in a reductionist way as meaning nothing more than access to compulsory education for the purposes of learning to read and write.

In the second case, the teaching of human rights is not at all widespread and is spreading very slowly since it does not respond to the agendas of the various educa- 
tional interests. The teaching of human rights has never been identified in a school subject at any level of the curriculum or educational system. Even where educational legislation has provided for the presence of issues related to the teaching of values, the teaching of human rights has not held an important place in the curriculum. In contrast, this has occurred with regard to education on peace, road safety, or environmental and inter-cultural education. The new government does, however, have plans to include a proposal for a compulsory school subject on citizenship values with particular emphasis on the promotion of gender equality.

Interestingly, human rights have always appeared as a form of cultural content in basic curricular subjects such as history, philosophy, ethics, and in some cases, incredibly, in legislative texts relating to music, the plastic arts, or physical education. They are very rarely present among general educational aims as a key component of personal development. When present human rights are in the non-compulsory aspects of education. Thus, in the latest educational reform, temporarily paralysed by the new government, human rights appear as an educational aim only at the upper high-school level (bachillerato), which commences at age 16. Katarina Tomasevski recently said in an interview: "Spain is the only European country which does not have a school subject to explain to children and young people what we mean when we talk of human rights" (ABC, 18-5-2004, p.56).

Towards the end of 2002, Amnesty International (Spain) published a report - available on their website - concerning the situation of the teaching of human rights in the Faculties and Schools of Education in our country. The conclusions are titled "Failed Subject": there is not one single subject on human rights in the courses offered to pedagogues, teachers, or social educators. It is noteworthy that all institutions have powers to define certain matters of special interest in the study plan other than those considered to be compulsory by the government. This report also states that the Spanish government has failed to comply with all the proposals agreed by the U.N. to promote human rights teaching during the decade from 1995-2004.

These reports lead to an interesting pedagogical tension because they have appeared, paradoxically, when there is an increasing demand for human rights to be taught, as well as for the publication of textbooks and other resources materials to be used in different educational contexts. This tension arises because in our country we are in a period of transition. We are at a moment where there is an incongruity between the expectations of educational interests regarding the need for teaching human rights, and their absence in the legislated curriculum. While there is an element of truth in all of this, there is a more significant explanation. Currently, human rights constitute the ultimate index of the moral progress of our societies. Their presence is so important that they monopolize political, social, and cultural debate. They are always there, allpervasive, in all issues, in the mouths of almost all political factions, and are used to support contradictory arguments. They can adopt numerous faces because there are numerous horizons that they lead to. We can find them in any element of the educational process, in any subject across the curriculum, and in any kind of education. They can be found in the articles of the medical code of ethics and, for the sake of 
argument, in refuse-collection policies. We could say, in conclusion, that they are considered to be so natural, so rooted in the conditions of possibility of democratic societies, that they are mistakenly regarded as being taken for granted and known about; they are there, like the air that we breathe.

This position is, however, an error. Human rights are not so natural, and they are not self-sustaining. They may be lost; their expansion may recede; we may become insensitive to their violation. As teachers, we therefore need to take stock, not just of their generic importance (who could possibly deny their importance for co-existence?) but rather as a condition for the possibility of designing educational curricula and projects. We believe that this requires two lines of action. On the one hand, to continue designing teaching materials in accordance with educational levels which help teachers to commence and maintain human rights education. On the other hand, more importantly in our present context, to link the concept of an educated person to these rights, and to the values on which human rights are based. As pedagogues, we should acknowledge that on occasions, what is surprising is not that they are not taught: what is surprising is that theoretical reflections on the concept of education and educated persons do not contain, as a constitutive element, any reference to the meaning of human rights. If democratic theory and practice can no longer be conceived of without human rights, why should the same not be the case for education?

\section{A Perspective from Canada}

The commitment of Canada to human rights in the modern era began with the framing, under the aegis of the United Nations, of the Universal Declaration of Human Rights [UDHR] following the Second World War. John Humphrey, a law professor from McGill University, joined the Human Rights Commission of the fledging United Nations and, working with a number of committed people including Eleanor Roosevelt, was largely responsible for drafting the document that became the Universal Declaration. The story is detailed in his book Human Rights and the United Nations: a great adventure (1984). Since that time Canada has supported the work of the United Nations and has become a signatory to the several and various United Nations treaties and conventions that are now part of the extensive legacy of that early vision.

Within Canada itself, the respect extended to human rights has also grown following the approval of the UDHR. As a state party to these various treaties and conventions, Canada is expected to adhere to the principles laid out in these documents. Although on some occasions slow to implement the agreements, Canada has by and large moved in the direction of enshrining and fostering education about human rights. The commitment to human rights has taken two forms. The first was the development of jurisdictional - federal and provincial - codes of human rights that proscribe discrimination in a variety of arenas of social life, like employment, public housing, accommodations in hotels and educational institutions inter alia. The second and more significant development was the inclusion of the Charter of Rights and Freedoms [Charter] in the 1982 Constitution Act. This Act patriated Canada's constitutional authority from Westminster in the United Kingdom. 
The inclusion of the Charter has precipitated a spate of judicial activity since that time as the various rights and freedoms in the Charter have been used to challenge a whole array of social practices including some in education. Indeed, as Michael Ignatieff argues in his book The Rights Revolution (2000), the spate of activity has ushered into Canada a full-blown revolution in human rights such that "...Canada has become one of the most distinctive rights cultures in the world." Ignatieff identifies four distinctive elements of the Canadian rights culture. He posits first that on moral issues like abortion, capital punishment and gay rights, Canadian legal codes are liberal, secular, and pro-choice. Indeed, at the time of writing an increasing number of provinces are recognizing the right of homosexual couples to marry. Second, Canadian culture is social democratic in its approach to welfare and social assistance. Third, the Canadian legal and constitutional tradition recognizes the group rights of distinguishable groups like linguistic minorities and aboriginal peoples. Fourth, Canada is distinctive in that the federal government has laid out the terms and conditions that must be met should a province or territory wish to secede from confederation. In addition, the corpus of judicial decisions emanating from the Supreme Court of Canada is attracting worldwide attention as examples of judicial reasoning in matters of human rights. So the legal context of rights in Canada is particularly vital as the Supreme Court and other courts of competent jurisdiction breathe life into the Charter.

Notwithstanding the impact of the Charter, it is of course still the case that the authority to legislate in matters of education remains a provincial prerogative in Canada. So the federal governement has no authority to enter the educational policymaking arena. Nevertheless, the federal government does become involved through initiatives that clearly lie within its purview. The primary responsibility for teaching about human rights rests with the provincial governments through the curricula that the provincial Ministries of Education create and authorize for use in provincial schools. While the curricula vary somewhat from province to province, all provincial curricula provide for the teaching of human rights at different levels usually through the Social Studies curriculum or through senior level courses in Law or Law \& Society. In addition, the Canadian Human Rights Foundation has an active program of human rights education as do its provincial counterparts.

While it is never prudent to take the protection and institutionalization of human rights for granted, there is a growing consciousness about human rights in Canada. Breaches of human rights like outbursts of anti-Semitism do, regrettably, still occur. These serve to remind us to continue our vigilance and to promote further education about human rights in all walks of life and in all sectors of society. Concern respecting the preservation and education about human rights undergird the papers from Canada included in this special issue.

\section{A Multiple Approach to Human Rights and Education}

As we have already noted, even if the contributions included in this issue of Encounters on Education / Encuentros sobre Educación / Rencontres sur l'Éducation, come from different places and traditions, they are intended to open a fruitful academic dialogue 
around a theme with a universal aspiration. The papers present a diverse array of current work and concerns about human rights and education. Some of them explore fundamental questions on the situation and pedagogical meaning of the rights, whereas others focus on more specific aspects of human rights.

The first section begins with a paper by Maryse Paquin and Sébastien Poirier from the University of Ottawa. They analyze the status of human rights and citizenship education in three Canadian provinces - Manitoba, Quebec and Ontario - and display and discuss the different approaches in each province. Diego Iturralde and Ana María Rodino report on the situation of human rights education in 19 Latin American countries, which provides a very clear snapshot of this issue in an extremely important region of the world. The article analyses the theoretical bases, the development, the evaluation indicators, the strategies for obtaining information, and the conclusions regarding, on the one hand, legislative developments in human rights education, and on the other hand, advances in the curriculum and in the textbooks for teaching them. Brian Orend from the University of Waterloo offers a philosophical analysis of human rights education and argues that the current focus on legislative enactments and the purely legal aspects of human rights in educational settings is too narrow. He proposes instead a pedagogy that recognizes the universal and rational character of human rights set within a broader, more holistic conception of human rights. Finally, the contribution by Juan Escámez, from the University of Valencia, focuses on the theoretical and practical promotion of what is known as the third generation of human rights. In established democracies, the teaching of human rights is aimed towards individual and social projects based on solidarity, on a healthy environment, on the development of collectivities, and on peace. Of particular importance and educational value is the link drawn by professor Escámez between the legal significance of these rights and their educational implementation.

With regard to human rights and education in more specific human right contexts, the paper by Ana Ayuste and Montserrat Payá, from the University of Barcelona, deals with one of the most discriminated-against and oppressed minorities in Europe, namely female gypsies. The analyses reported are the product of a research, development and innovation study. Working from the perspective of critical pedagogy, Ayuste and Payá seek to identify the barriers in Spain to education for young and adolescent gypsy girls, to pinpoint the most salient factors rooted in both gypsy and non-gypsy cultures contributing to their exclusion from education, and to propose a suitable transformation for each one. Paul Clarke from the University of Regina and Bruce MacDougall from the University of British Columbia, examine a recent legal case on the cutting edge of human rights issues in Canada. This case involves equality rights and the interests of gays and lesbians versus the freedom of speech of a teacher with homophobic views. María Rosa Buxarrais and Miquel Martínez, from the University of Barcelona, focus on children's rights in the context of the challenges posed for child development by rapid information and technological change. The authors argue that to avoid the possible exclusionary effects of the new systems of information and technology requires a much deeper understanding of the conditions of education and learning 
in childhood. The last contribution, by Donato Tarulli and his colleagues from Brock University address the issue of human rights for persons with intellectual disabilities. They descibe a human rights project under development in Canada designed to promote human rights awareness among perosns with such disabilities.

The editors of this special issue on Human Rights and Education wish to conclude this introduction by thanking the management of this prestigious international journal for the opportunity they have offered us to address what is, in all certainty, one of the most important pedagogic issues in education in the twenty-first century. Likewise, we would not wish to conclude without special thanks for the interesting contributions made by the various authors who, without exception, have shown their interest and willingness to participate in this project. We extend our thanks and appreciation to all these people. 